\title{
FEED FORWARD BACK PROPAGATION NEURAL NETWORK COUPLED WITH RICE DATA SIMULATOR FOR PREDICTION OF RICE PRODUCTION IN TAMILNADU
}

\author{
S.Arun Balaji ${ }^{1}$ and K.Baskaran ${ }^{2}$ \\ ${ }^{1} \mathrm{PhD}$ Scholar, Computer Science \& Engineering, Karpagam University, Coimbatore. \\ ${ }^{2} \mathrm{PhD}$ Research Director and Associate Professor, Dept. of Computer Science \& \\ Information Technology, Government College of Technology, Coimbatore, India.
}

\begin{abstract}
This paper is the continuation of the paper published by the authors Arun Balaji and Baskaran [2]. Multiple linear regression (MLR) equations were developed between the years of rice cultivation and Feed Forward Back Propagation Neural Network (FFBPNN) method of predicted area of rice cultivation / rice production for different districts pertaining to Kuruvai, Samba and Kodai seasons in Tamilnadu. The average $r^{2}$ value in area of cultivation is 0.40 in Kuruvai season, 0.42 in Samba season and 0.46 in Kodai season, where as the $r^{2}$ value in rice production is 0.31 in Kuruvai season, 0.23 in Samba season and 0.42 in Kodai season. The Rice Data Simulator (RDS) predicted the area of rice cultivation and rice production using the MLR equations developed in this research. The range of average predicted area for Kuruvai, Samba and Kodai seasons varies from 12052.52 ha to 13595.32 ha, 48998.96 ha to 53324.54 ha and 4241.23 ha to 6449.88 ha respectively whereas the range of average predicted rice production varies from 45132.88 tonnes to 46074.48 tonnes in Kuruvai, 128619 tonnes to 139693.29 tonnes in Samba and 15446.07 to 20573.50 tonnes in Kodai seasons. The mean absolute relative error (ARE) between the FFBPNN and multiple regression methods of prediction of area of rice cultivation was found to be $15.58 \%$, $8.04 \%$ and $26.34 \%$ for the Kuruvai, Samba and the Kodai seasons respectively. The ARE for the rice production was found to be 17\%, $11.80 \%$ and $24.60 \%$ for the Kuruvai, Samba and the Kodai seasons respectively. The paired t test between the FFBPNN and MLR methods of predicted area of cultivation in Kuruvai shows that there is no significant difference between the two types of prediction for certain districts.
\end{abstract}

\section{Keywords}

Rice Data Simulator, Neural Network, Multiple linear regression, Prediction of rice production

\section{INTRODUCTION}

Rice is one the stable food for many Asian countries. Rice is the main food consumed in south India including the state of Tamilnadu. Rice production is a complex process involving the different types of soil, varieties of seeds, weather conditions, seasons in a year, varied land and water management practices, pest and disease management techniques, manure and fertilizer management methods, weed management and timeliness management of different unit operations like sowing the seeds, growing of rice and harvesting practices. Hence, rice production is a non 
linear, parallel and interconnected process. Many mathematical and statistical methods have been developed to predict rice production based on different parameters. All these methods do not involve a non linear modeling approach. The present study is based on non linear, highly parallel and interconnected networking approach of using artificial feed forward back propagation neural network (FFBPNN) with sigmoid activation function coupled with rice data simulator. The input data like area of rice cultivation in hectare and rice production in tonnes for three seasons namely Kuruvai, Samba and Kodai for the 31 districts of Tamilnadu for five years from 2005-06 to 2008-09 were collected from the Seasons and Crop report [1] published by the Government of Tamilnadu. The authors of this paper already published [2] with more details pertaining to the prediction of rice data using FFBPNN. The published paper revealed the fact that the initial error computed for the FFBPNN output from the original input data for the entire variable like Kuruvai area and its production, Samba area and its production and the Kodai area and its production started at 0.0000548 at the first iteration and the error of all the variables became 0 at $18^{\text {th }}$ iteration. The error reduction pattern for the entire six variables followed the same curve linear path. This showed that the non linearity and complexity of input data were reduced and smoothened after the transformation by the sigmoid activation function multiplied by weights and subsequent updated weights. This paper is the continuation of the already published paper. The overall objective of the present study is coupling of Rice Data Simulator (RDS) with FFBPNN for simulating rice area of cultivation and rice production for the for five years of data captured, which is from 2005-06 to 2008-09. The specific objectives of this paper are:

1 To develop the multiple linear regression equations between the years and FFBPNN method of predicted area of rice cultivation / rice production

2 To predict the area of rice cultivation and rice production from the multiple regression equations developed

3 To compute the absolute relative error (ARE) between the FFBPNN method of prediction and multiple regression method of prediction and its analysis

4 To test the statistical significance using paired t-test between the FFBPNN method of prediction and multiple regression method of prediction and its analysis

\section{REVIEW OF LITERATURE}

According to F. A. Makinde, C. T. Ako et al [3], the Feed-Forward Back-Propagation Neural Network (FFBPNN) model was used to model the under saturated crude oil viscosity from the Niger Delta region of Nigeria. The FFBPNN is a multi- layered architecture where information flows from the input to the output through at least one hidden/middle layer. Each layer contains neurons that are connected to all neurons in the neighboring layers. The connections have numerical values (weights) associated with them which will be adjusted during the training phase. Checking the results of this model shows that the obtained results for under saturated oil viscosities in this work are in agreement with experimental data compared with the empirical correlations considered in this work. The newly developed FFBPNN model for predicting under saturated crude oil viscosity shows good results compared to the empirical correlations. The FFBPNN model achieved an average absolute relative error of 0.01998 and the relative deviation correlation coefficient of 0.999 as compared to existing empirical correlations. From the cross plots for the FFBPNN model and empirical correlations against their experimental values, the FFBPNN model data points' performance was excellent.

Khashei-Siuki et al [4] studied the prediction of dry land wheat yield based on the daily available weather data and yearly agricultural data with several nonlinear modeling techniques for an arid and semi-arid climate. Two models were used to predict the wheat yield. They were Adaptive 
Neuro-Fuzzy Inference Systems (ANFIS) model and Artificial Neural Network with MultiLayered Preceptron (MLP) model. The study used seven meteorological variables namely precipitations, humidity, evapotranspiration, net radiation, maximum and minimum temperature, and dew temperature for the estimation of dry land wheat yield. ANFIS method provided a general framework for the combination of ANN and fuzzy systems capabilities. The performance of ANFIS model was more pronounced than MLP in testing period. It was concluded that ANFIS model has the ability for precise estimation of dry land wheat yield, while MLP being the most suitable model for this study area. It was reported that there is a lack of comparative studies of different models. Their study used different expert nonlinear models to predict dry land wheat yield. It was reported that MLP and ANFIS techniques could be used in many fields including scheduling, politics, design, and various other analyses. These models can also be integrated into modules for application in general economic models.

Sanjay R. Bhatikar et al [5] reported the challenging problem of modeling of the Energy Storage System (ESS) of a Hybrid Electric Vehicle (HEV).The problem is not amenable to physical modeling without simplifying assumptions that compromise the accuracy of such models. It was reported that the application of an artificial neural network (ANN) was used to model the ESS. The model maps the system's state-of-charge (SOC) and the vehicle's power requirement to the bus voltage and current. It revealed that ANN models can accurately capture the complex, nonlinear correlations accurately. It was reported that smart select is a technique used for designing ANN training data. The underlying philosophy of Smart Select is to design the training data set such that it is uniformly distributed over the entire range of an appropriate ANN output variable, which is typically the variable that is most difficult to model. It was found that the training data that were uniformly distributed over the current range. It was reported that smart-select is economical in comparison with conventional techniques for selection of training data. The study reported that an artificial neural network model was developed with 2 inputs, 3 hidden neurons and 2 outputs utilizing only 1583 of the available 32,254 points. When validated on the remaining points, its predictive accuracy, measured by R-squared error, was 0.9978. Also, it was reported that there was an integration of the ANN model of the ESS into the MATLAB-SIMULINK environment of NREL's vehicle simulation software, ADVISOR. This yields a simpler implementation of the ESS module in ADVISOR and does away with certain tenuous assumptions in the original implementation. The report showed that there was dramatic reduction in the size of the training data set by the application of the model modifier approach developed by the research group at the University of Colorado at Boulder.

Using ANNs and Fuzzy Logic, Mayilvaganan, and Naidu [6] have tried to predict ground water level and they have concluded that ANN performs better than Fuzzy Logic.

It has been also proved by the contribution of Karmakar et al., [7] that Back Propagation Network forecast are more efficient technique over the statistical model for forecasting long-range monsoon rainfall over the high resolution geographical region such as district or sub-division level. He has successfully obtained global minima up to the level of $10^{-04}$ during the training period. And also has obtained more than $80 \%$ accuracy in prediction during the independent period. 


\section{METHODOLOGY}

\subsection{Prediction of rice data using Feed Forward Back Propagation Neural Network}

As reported by Arun Balaji and Baskar [2], a computer program in C++ was developed to read the training data for the FFBPNN. The five years mean area of cultivation and five year mean rice production for the all the districts cultivating rice in Kuruvai, Samba and Kodai seasons of the year 2005 to 2009 was taken as training data. The training data contains the six data items like area and production of rice for three seasons for each district. The FFBPNN system consists of two neurons per season. The first neuron is made of area of rice cultivation in a season and the second neuron is made up of rice production in the same season. Hence, there are two neurons per season. Tamilnadu is producing rice in three seasons. This leads to a total of six neurons. The Feed Forward Back Propagation Neural Network (FFBPNN) to predict rice area of cultivation and rice production is shown in Figure 1 in appendix 1. Readers of this paper are requested to go through the first paper published by the same authors Arun Balaji and Baskaran [2] for more details.

\subsection{Rice Data Simulator (RDS)}

RDS is software created in C++ for the simulation of rice data. RDS used the input data either area of rice cultivation in hectare or rice production in tonnes for different districts of Tamilnadu cultivating rice in Kuruvai, Samba and Kodai seasons for the five years 2005 to 2009. RDS was developed based on the multiple linear regression (MLR) analysis of the set of data pertaining to year of rice cultivation ( $\mathrm{x}$ variable) and either area of rice cultivation or rice production predicted from FFBPNN (y variable). The predicted rice data from the FFBPNN for either area of rice cultivation or rice production will be the input into RDS system.. The following is the steps involve in the prediction of rice data using RDS.

\subsubsection{Fitting the multiple linear regression (MLR) equations between years and the area of rice cultivation for three seasons}

The years of rice cultivation from 2005 to 2009 is taken as independent variable $\mathrm{x}$. The number of observation is $\mathrm{N}$, which is 5 in the present case. The y1, y2 and y3 vectors are the area of rice cultivation in hectare for Kuruvai, Samba and Kodai seasons respectively for a district. Thus RDS provide three sets of multiple regression equations for the area data. Fitting regression equation between independent variable $\mathrm{x}$ and dependent variable $\mathrm{y}$ will give the equation of the form $\mathrm{y}=\mathrm{a}$ $+\mathrm{bx}$. The $\mathrm{a} 1, \mathrm{a} 2$ and $\mathrm{a} 3$ are the constants and $\mathrm{b} 1, \mathrm{~b} 2$ and $\mathrm{b} 3$ are regression coefficients computed based on the theory of fitting regression equation. The values of $r_{1}{ }^{2}, r_{2}{ }^{2}$ and $r_{3}{ }^{2}$ are coefficient of correlation computed to understand the type of fitting. The various generic formulae used to fit the regression equation between $\mathrm{x}$ and $\mathrm{y}$ is given below:

Sum of Product of $\mathrm{X}$ and $\mathrm{Y}=\mathrm{SPXY}=\sum X Y-\frac{\sum X \sum Y}{N}$

Sum of square of $\mathrm{X}=\mathrm{SSX}=\sum X^{2}-\frac{\left(\sum X\right)^{2}}{N}$

Sum of square of $\mathrm{Y}=\mathrm{SSY}=\sum Y^{2}-\frac{\left(\sum Y\right)^{2}}{N}$

$\mathrm{b}=\frac{S P X Y}{S S X}, \quad \bar{x}=\frac{\sum x}{N}, \quad \bar{y}=\frac{\sum y}{N} \quad$ and $\quad \mathrm{a}=\bar{y}-\mathrm{b} \bar{x}$

Using the calculated values of $a$ and $b$, the regression equation can be written as $y=a+b x$.

Coefficient of Correlation $\mathrm{r}=\frac{S P X Y}{\sqrt{S S X . S S Y}}$ and $r^{2}=\frac{S P X Y^{2}}{S S X . S S Y}$ 
Thus the RDS provides the following set of multiple linear equations.

$\mathrm{y} 1=\mathrm{a} 1+\mathrm{b} 1 \mathrm{x}$ for area of Kuruvai season

$\mathrm{y} 2=\mathrm{a} 2+\mathrm{b} 2 \mathrm{x}$ for area of rice in Samba season

$\mathrm{y} 3=\mathrm{a} 3+\mathrm{b} 3 \mathrm{x}$ for area of rice in Kodai season

\subsubsection{Fitting the multiple linear regression (MLR) equations between years and the rice production for three seasons}

The years of rice production from 2005 to 2009 is taken as independent variable x. The number of observation is $\mathrm{N}$, which is 5 in the present case. The y4, y5 and y6 vectors are the rice production in tonnes in Kuruvai, Samba and Kodai seasons respectively. Fitting regression equation between independent variable $\mathrm{x}$ and dependent variable $\mathrm{y}$ will give the equation of the form $\mathrm{y}=\mathrm{a}+\mathrm{bx}$. The $\mathrm{a} 4, \mathrm{a} 5$ and $\mathrm{a} 6$ are the constants and $\mathrm{b} 4, \mathrm{~b} 5$ and $\mathrm{b} 6$ are regression coefficients computed based on the theory of fitting regression equation. The values of $r_{4}^{2}, r_{5}^{2}$ and $r_{6}^{2}$ are coefficient of correlation computed to understand the type of fitting. The various generic formulae used to fit the regression equation between $\mathrm{x}$ and $\mathrm{y}$ was given under section 3.2.1. Thus the RDS uses the following set of multiple linear equations:

$\mathrm{y} 4=\mathrm{a} 4+\mathrm{b} 4 \mathrm{x}$ for rice production in Kuruvai season

$\mathrm{y} 5=\mathrm{a} 5+\mathrm{b} 5 \mathrm{x}$ for rice production in Samba season

$\mathrm{y} 6=\mathrm{a} 6+\mathrm{b} 6 \mathrm{x}$ for rice production in Kodai season

\subsubsection{Prediction of the area of rice cultivation from the MLR}

The prediction of area of rice cultivation in hectare is obtained by inserting $\mathrm{x}=(2005,2006$, 2007, 2008 and 2009) in the three equations $y 1=a 1+b 1 x$ for area of rice in Kuruvai season, $y 2$ $=\mathrm{a} 2+\mathrm{b} 2 \mathrm{x}$ for area of rice in Samba season and $\mathrm{y} 3=\mathrm{a} 3+\mathrm{b} 3 \mathrm{x}$ for area of rice in Kodai season.

\subsubsection{Prediction of rice production from the MLR}

The prediction of rice production in tonnes is obtained by inserting $\mathrm{x}=(2005,2006,2007,2008$ and 2009) in the three equations $\mathrm{y} 4=\mathrm{a} 4+\mathrm{b} 4 \mathrm{x}$ for rice production in Kuruvai season, $\mathrm{y} 5=\mathrm{a} 5+$ $\mathrm{b} 5 \mathrm{x}$ for rice production in Samba season and $\mathrm{y} 6=\mathrm{a} 6+\mathrm{b} 6 \mathrm{x}$ for rice production in Kodai season.

\subsection{Computation of Absolute Relative Error (ARE) for area of cultivation}

ARE between the FFBPNN method of predicted area and the multiple regression method of predicted area was carried out using the formula given below:

$$
A R E \%=\frac{1}{N} \sum_{i=1}^{N} \frac{(F F B P N N \text { predicted area }-M L R \text { predicted area })}{F F B P N N \text { prediced area of rice cultivation }} \times 100
$$

Where $\mathrm{N}$ is the total number of data points. ARE in percent were computed for different districts and different seasons. 
International Journal of Computer Science, Engineering and Information Technology (IJCSEIT), Vol. 4, No.5, October 2014

\subsection{Computation of Absolute Relative Error (ARE) for rice production}

ARE between the FFBPNN method of predicted rice production and the multiple regression method of predicted rice production was carried out using the formula given below:

$$
\begin{aligned}
& A R E \% \\
& =\frac{1}{N} \sum_{i=1}^{N} \frac{(F F B P N N \text { predicted rice production }-M L R \text { predicted rice production) }}{\text { FFBPNN prediced rice production }} \times 100
\end{aligned}
$$

Where $\mathrm{N}$ is the total number of data points. ARE in percent were computed for different districts and different seasons.

\subsection{Testing the statistical significance between the FFBPNN and multiple regression methods of predicted data}

The t-test is used to test the significance between two sets of paired data. The pair consists of FFBPNN and multiple regression methods of predicted area of cultivation. The calculated t value for $\mathrm{N}$ observations was computed as follows:

Let $X$ is the array of values of FFBPNN method of predicted area of cultivation

Let $\mathrm{Y}$ is the array of values of multiple regression method of predicted area of cultivation

$\mathrm{D}=\mathrm{X}-\mathrm{Y}$, Compute $\sum D, \sum D^{2}$ and $\bar{D}=\frac{\sum D}{N}$ where $\mathrm{N}$ is the number of observations

Standard Deviation $(\mathrm{SD})=\sqrt{\frac{\sum D^{2}-\frac{\left(\sum D\right)^{2}}{N}}{(N-1)}}$

Standard Error $\mathrm{SE}=\frac{S D}{\sqrt{N}}$

Calculated Paired t value $=\frac{\bar{D}}{S E}$ It is a positive value. If negative value then omit the minus sign.

The Degrees of Freedom $=\mathrm{N}-1$

Refer the statistical $t$ table for $(\mathrm{N}-1)$ degree of freedom at $5 \%$ level of significance to get the table $\mathrm{t}$ value. If calculated $\mathrm{t}$ value is less than table $\mathrm{t}$ value then there is no significant difference between the FFBPNN method of predicted area of cultivation and the multiple regression method of predicted area of cultivation. . If calculated $t$ value is greater than table $t$ value then there is significant difference between the FFBPNN method of predicted area of cultivation and the multiple regression method of predicted area of cultivation. The same procedure is used to compute the $t$ value between the pair of FFBPNN method of rice production and multiple regression method of rice production.

\section{Results and Discussions}

Table A.1 in the appendix shows the FFBPNN method of predicted area of rice cultivation in hectare for different districts in three seasons. Table A.5 in the appendix shows the FFBPNN method of predicted rice production in tonnes for all the districts. As per the paper published by the authors [2], the FFBPNN prediction was carried out by updating the weights until the error is below the threshold value of $10^{-9}$, which was done by repeating the back propagation for 18 
iterations. This predicted data was compared with the observed data collected for area and production of rice in different districts. It was found that both observed and FFBPNN way of predicted data are 100\% in agreement for three seasons for the years 2005 to 2009. It was found that the FFBPNN method of prediction is exactly the same as observed area. There is $100 \%$ perfect prediction. But in practice, rice area of cultivation and subsequent rice production varies based on the variety of seed, availability of water, land and crop management considerations. Hence, the authors wished to couple a more scientific method of realistic prediction by introducing the development of RDS as per section 3.2. Readers of this paper are requested to go through the author's previous publication [2]. The present results and discussion explains the following specific issues:

- Development of MLR equations between the years of rice cultivation and FFBPNN method of predicted area of rice cultivation / rice production

- Prediction of area of rice cultivation and rice production from the MLR equations developed

- Computation of ARE between the FFBPNN method of prediction and MLR method of prediction and its analysis

- Testing the statistical significance using paired t-test between the FFBPNN method of prediction and MLR method of prediction and its analysis

\subsection{Development of multiple linear regression equations}

As explained in section 3.2.1 and 3.2.2, fitting the MLR equations between years and the area of rice cultivation and also between years and the rice production for three seasons of different districts of Tamilnadu were carried out.

\subsubsection{MLR equations developed between and FFBPNN method of predicted area of cultivation}

The Rice Data Simulator (RDS) provides the following set of MLR equations for the area of rice cultivation:
$y 1=a 1+b 1 x$
(1) Kuruvai season
$y 2=a 2+b 2 x$
(2) Samba season
$y 3=a 3+b 3 x$
(3) Kodai season

The above set of MLR equations fitted between years in $\mathrm{x}$ axis and the FFBPNN method of predicted area of rice cultivation in y axis is shown in Table A.2 of the appendix. The values of a1 and b1 for Kuruvai season, a2 and b2 for Samba season and a3 and b3 for the Kodai seasons are shown in Table A.2. The summary of the values of $r^{2}$ for the set of MLR equations for area of rice cultivation in three seasons are given in Table 1: 
Table 1: Values of $r^{2}$ for the set of MLR equations between years and FFBPNN method of predicted area of cultivation

\begin{tabular}{|c|c|c|c|}
\hline \multirow[t]{2}{*}{$\begin{array}{l}\text { Statistical } \\
\text { Parameters }\end{array}$} & \multicolumn{3}{|c|}{$\begin{array}{l}\text { Values of } r^{2} \text { for regression equation of area of rice cultivation (Table } \\
\text { A.2) }\end{array}$} \\
\hline & Kuruvai season & Samba season & Kodai season \\
\hline Minimum & 0.00 & 0.00 & 0.04 \\
\hline Maximum & 0.98 & 0.99 & 0.89 \\
\hline Average & 0.40 & 0.42 & 0.46 \\
\hline Std.deviation & 0.35 & 0.27 & 0.25 \\
\hline $\begin{array}{l}\text { No. of } \\
\text { districts }\end{array}$ & 25 & 28 & 26 \\
\hline
\end{tabular}

Table 1 shows that the $r^{2}$ values are widely varying between a minimum of 0 to a maximum of 0.99 . If the $r^{2}$ values are nearer to 1 , it means that the fitting is perfect. If the $r^{2}$ values are nearer to 0 , it means the there is a poor fitting of the regression equation. Table A.2 shows that some districts has perfect fitting while some are not having perfect fitting. This is unavoidable in the area of rice cultivation because of the reason that agriculture in Tamilnadu is a gamble with monsoon rains. Crop failure occurs at different stages of crop growth due to scarcity of irrigation water, lack of sufficient nutrients, problems of weeding, pest and diseases etc. It was found that there is wide variation in data collected for different years for the districts mainly due to non availability of water in time. The average $r^{2}$ value in area of cultivation is 0.40 in Kuruvai season, 0.42 in Samba season and 0.46 in Kodai season. The standard deviation of $r^{2}$ value in area of cultivation of rice varies from 0.25 in Kodai season to 0.35 in Kuruvai season. All these discussion implies that there are wide fluctuations in data pertaining to area of rice cultivation in different years for some of the districts. However, the researcher has fitted the MLR equations by using non linear FFBPNN prediction coupled with RDS to get a scientific way of predicting the area of cultivation.

\subsubsection{MLR equations developed between the years and the FFBPNN method of predicted rice production}

The RDS provides the following set of MLR equations for rice production:
$y 4=a 4+b 4 x$
(4) Kuruvai season
$y 5=a 5+b 5 x$
(5) Samba season
$y 6=a 6+b 6 x$
(6) Kodai season

The set of MLR equations were fitted between years of rice production in $\mathrm{x}$ axis and the FFBPNN method of predicted rice production in tonnes in y axis, which is shown in Table A.6 of the appendix. The values of a4 and b4 for Kuruvai season, a5 and b5 for Samba season and a6 and b6 for the Kodai seasons are shown in Table A.6. The summary of the values of $r^{2}$ for the set of MLR equations for rice production in three seasons are given in Table 2: 
International Journal of Computer Science, Engineering and Information Technology (IJCSEIT), Vol. 4, No.5, October 2014

Table 2: Values of $\mathrm{r}^{2}$ for the set of MLR equations between years and FFBPNN method of predicted rice production

\begin{tabular}{|l|c|c|c|}
\hline \multirow{2}{*}{$\begin{array}{l}\text { Statistical } \\
\text { Parameters }\end{array}$} & \multicolumn{3}{|c|}{ Values of $\mathrm{r}^{2}$ for regression equation of rice production (Refer Table A.6) } \\
\cline { 2 - 4 } Minimum & Kuruvai season & Samba season & Kodai season \\
\hline Maximum & 0.00 & 0.00 & 0.00 \\
\hline Average & 0.87 & 0.98 & 0.99 \\
\hline Std.deviation & 0.31 & 0.23 & 0.42 \\
\hline No. of districts & 0.30 & 0.23 & 0.27 \\
\hline
\end{tabular}

Table 2 shows that the $r^{2}$ values are widely varying between a minimum of 0 to a maximum of 0.99. It is found from Table A.6 that some districts in a season has perfect fitting with $r^{2}$ value nearing 1, while some other districts in a season are not having perfect fitting because $r^{2}$ is nearing 0 . It is found that the average $r^{2}$ value in rice production is 0.31 in Kuruvai season, 0.23 in Samba season and 0.42 in Kodai season. The standard deviation of $\mathrm{r}^{2}$ value in rice production varies from 0.23 in Samba season to 0.30 in Kuruvai season. This discussion implies that there are wide fluctuations in data pertaining to rice production in different years for a district due to complexities of water scarcity, rice husbandry and management.

\subsection{Prediction of area of rice cultivation and rice production from the MLR equations developed}

The predicted area of rice cultivation was computed for 2005 to 2009 by inserting year of cultivation from 2005 to 2009 in the MLR equations shown in Table A.2 of appendix for three seasons. Similarly, the predicted rice production was computed by inserting year of cultivation from 2005 to 2009 in the MLR equations shown in Table A.6 of appendix for three seasons.

\subsubsection{Prediction of area of rice cultivation from the MLR}

The predicted areas of cultivation are shown in Table A.3 of the appendix. The statistics of the predicted area of cultivation from the set of MLR equations as per Table A.3 for three seasons are given in Table 3. 
International Journal of Computer Science, Engineering and Information Technology (IJCSEIT), Vol. 4, No.5, October 2014

Table 3: Statistics of the predicted area of cultivation from MLR for three seasons

\begin{tabular}{|l|l|l|l|l|l|}
\hline Parameter & \multicolumn{5}{l}{ Statistics of the predicted area of cultivation from MLR, hectare } \\
\hline Year & 2005 & 2006 & 2007 & 2008 & 2009 \\
\hline & Kuruvai season & 905 & 634 & 363 \\
\hline Minimum & 1369 & 1176 & 39984 & 39097 & 38210 \\
\hline Maximum & 41757 & 40870 & 12828.96 & 12445.84 & 12062.52 \\
\hline Mean & 13595.32 & 13212.08 & 10644.48 & 10499.97 & 10403.82 \\
\hline Std. deviation & 11070.78 & 10835.56 & \multicolumn{5}{l|}{} \\
\hline & Samba season & 3071 & 2180 & 1288 \\
\hline Minimum & 4854 & 3963 & 142823 & 143722 & 144621 \\
\hline Maximum & 141026 & 141925 & 51271.5 & 50245.11 & 48998.96 \\
\hline Mean & 53324.54 & 52298 & 44841.75 & 45500.54 & 46484.37 \\
\hline Std. deviation & 43865.85 & 44295.53 & & \\
\hline & Kodai season & 257 & 178 & -225 \\
\hline Minimum & 94 & 34069 & 33103 & 32137 & 31171 \\
\hline Maximum & 35035 & 5897.69 & 5345.62 & 4793.50 & 4241.23 \\
\hline Mean & 6449.88 & 5897 & 6957.60 & 6484.13 \\
\hline Std. deviation & 8939.42 & 8206.36 & 7539.40 & \\
\hline
\end{tabular}

Table 3 brings out the fact for the Kuruvai season the minimum range of predicted area of rice cultivation varies from 363 ha to 1369 ha. It was also found out that the maximum predicted area varies from 38201 ha to 41757 . The average predicted area varies from 12052.52 ha to 13595.32 ha. Similarly, the standard deviation varies from 10403.82 ha to 11070.78 ha. It was found that the predicted area of rice cultivation gradually reduces from 2005 to 2009.

With regard to the Samba season, the minimum predicted area of rice cultivation varies from 1288 ha to 4584 ha. The maximum predicted area varies from 141026 ha to 144621 ha. The average predicted area varies from 48998.96 ha to 53324.54 ha. Similarly, the standard deviation varies from 43865.85 ha to 46484.37 ha.

With regard to the Kodai season, the minimum predicted area of rice cultivation varies from 225 ha for Coimbatore district in 2009 to 285 ha for Pudukottai district in 2007. The negative value of -225 ha cannot be acceptable prediction. The reason for the negative prediction of area is mainly due to wide variations of observed area of cultivation, which causes the regression equation not true representative to provide the correct prediction. This type of error can be avoided only when more input data are available to build the MLR equations. It was also found that the negative prediction of area was found only for Coimbatore and Namakkal districts. The prediction worked well for other districts. The maximum predicted area varies from 31171 ha to 35035 ha. The average predicted area varies from 4241.23 ha to 6449.88 ha and the standard deviation varies from 6484.13ha to 8939.42 ha.

\subsubsection{Prediction of rice production from MLR equations}

The predicted rice productions are shown in Table A.7 of the appendix. The statistics of the predicted rice production from the set of MLR equations for rice productions for three seasons are given in Table 4. 
International Journal of Computer Science, Engineering and Information Technology (IJCSEIT), Vol. 4, No.5, October 2014

Table 4: Statistics of the predicted rice production from MLR equations for rice production

\begin{tabular}{|l|l|l|l|l|l|}
\hline Parameter & \multicolumn{5}{|l|}{ Statistics of the predicted rice production from MLR equations, tonnes } \\
\hline Year & 2005 & 2006 & 2007 & 2008 & 2009 \\
\hline & Kuruvai season $(25$ districts produce rice) \\
\hline Minimum & 4176.00 & 3560.00 & 2945.00 & 2329.00 & 1714.00 \\
\hline Maximum & 144870.00 & 143808.00 & 142746.00 & 141683.00 & 140620.00 \\
\hline Mean & 45132.88 & 45368.24 & 45603.76 & 45839.12 & 46074.48 \\
\hline Std. deviation & 36372.19 & 35870.94 & 35735.12 & 35968.55 & 36564.20 \\
\hline & Samba season $(28$ districts produce rice) \\
\hline Minimum & 15444.00 & 14126.00 & 12808.00 & 11491.00 & 10173.00 \\
\hline Maximum & 398311.00 & 374415.00 & 353250.00 & 354486.00 & 355724.00 \\
\hline Mean & 136481.96 & 134516.29 & 139693.29 & 137727.54 & 128619.00 \\
\hline Std. deviation & 100385.35 & 98086.32 & 100527.40 & 99779.97 & 96856.03 \\
\hline & Kodai season $(26$ districts produce rice) & & \\
\hline Minimum & 417.00 & 898.00 & 980.00 & 633.00 & -97.00 \\
\hline Maximum & 107903.00 & 107148.00 & 106394.00 & 105639.00 & 104884.00 \\
\hline Mean & 20573.50 & 19291.49 & 18009.82 & 16727.93 & 15446.07 \\
\hline Std. deviation & 27967.16 & 26246.86 & 24704.93 & 23376.33 & 22299.37 \\
\hline
\end{tabular}

Table 4 brings out the fact that for the Kuruvai season, the minimum predicted rice production varies from 1747 tonnes to 4176 tonnes. It was also found out that the maximum predicted rice production varies from 140620 tonnes to 144870 tonnes. The average predicted rice production varies from 45132.88 tonnes to 46074.48 tonnes and the standard deviation varies from 35735.12 tonnes to36564.20 tonnes. It was found that the predicted rice production fluctuates every year and does not follow any particular trend because of complexities like weather and crop husbandry aspects.

With regard to the Samba season, the minimum predicted rice production varies from 10173 tonnes to 15444 tonnes. The maximum predicted rice production varies from 353250 tonnes to 398311 tonnes. The average predicted rice production varies from 128619 tonnes to 139693.29 tonnes and the standard deviation varies from 96856.03 tonnes to 100527.40 tonnes.

The predicted rice production from MLR for the Kodai season season is shown in Table A.7 of the appendix. The minimum predicted rice production varies from -97 tonnes for Namakkal district in 2009 to 980 tonnes in 2007 for Pudukottai district. The negative value of -97 tonnes cannot be acceptable prediction. The reason for the negative prediction of area is mainly due to wide variations of input observed rice production, which causes the regression equation not true representative to provide the correct prediction. This type of error can be avoided only when more input data is available to build the MLR equations. The maximum predicted rice production 104884 tonnes in 2009 to 109903 tonnes in 2005 . The average predicted rice production varies from 15446.07 tonnes to 20573.50 tonnes and the standard deviation varies from 22299.37 tonnes to 27967.16 tonnes.

\subsection{ARE between the FFBPNN and MLR methods of prediction}

As per the explanation in section 3.3 and 3.4, the ARE percent was calculated for area of rice cultivation between FFBPNN and MLR methods of predicted area of rice cultivation. The ARE percent for rice production was also calculated between FFBPNN and MLR methods of predicted rice production. 
International Journal of Computer Science, Engineering and Information Technology (IJCSEIT), Vol. 4, No.5, October 2014

\subsubsection{ARE between the FFBPNN and MLR methods of predicted area of cultivation}

ARE between the FFBPNN and MLR methods of predicted area of cultivation was worked out and shown in Table A.4 of the appendix. The summary of the ARE percent is given in Table 5.

Table 5: Summary of the ARE percent between the FFBPNN and MLR methods of predicted area of cultivation

\begin{tabular}{|l|l|l|l|}
\hline \multirow{2}{*}{$\begin{array}{l}\text { Statistical } \\
\text { parameters }\end{array}$} & \multicolumn{3}{|l|}{$\begin{array}{l}\text { ARE percent between the FFBPNN method and MLR methods of predicted } \\
\text { area of cultivation, \% }\end{array}$} \\
\cline { 2 - 4 } & Kuruvai season & Samba season & Kodai season \\
\hline Minimum & 2.04 & 0.61 & 2.61 \\
\hline Maximum & 63.48 & 38.13 & 58.71 \\
\hline Mean & 15.58 & 8.04 & 26.34 \\
\hline Std. deviation & 16.34 & 8.96 & 17.32 \\
\hline No. of districts & 25 & 28 & 23 \\
\hline Remarks & $\begin{array}{l}\text { During Kodai, Namakkal and Coimbatore districts has negative prediction } \\
\text { and Nagapattinam has high error \% . }\end{array}$ \\
\hline
\end{tabular}

Table 5 brings out the fact that the minimum, maximum and mean ARE percent was $2.04 \%$, $63.48 \%$ and $15.58 \%$ respectively for Kuruvai season, $0.61 \%, 38.13 \%$ and $8.04 \%$ respectively for Samba season and $2.61 \%, 58.71 \%$ and $26.34 \%$ respectively for Kodai season respectively. The reason for the highest error of $63.48 \%$ in Tiruvarur district in Kuruvai season,38.13\% in Coimbatore district during Samba season and 58.71\% in Salem district during Kodai season are due to wide fluctuations in the observed data.

\subsubsection{ARE between the FFBPNN and the MLR methods of predicted rice production}

ARE between the FFBPNN and MLR methods of predicted rice production were worked out and shown in Table A. 8 of the appendix. The summary of the ARE percent is given in Table 6.

Table 6 Summary of the ARE between the FFBPNN and the MLR methods of predicted rice production

\begin{tabular}{|c|c|c|c|}
\hline \multirow[t]{2}{*}{$\begin{array}{l}\text { Statistical } \\
\text { parameters }\end{array}$} & \multicolumn{3}{|c|}{$\begin{array}{l}\text { ARE between the FFBPNN and the MLR methods of predicted rice } \\
\text { production }\end{array}$} \\
\hline & Kuruvai season & Samba season & Kodai season \\
\hline Minimum & 3.96 & 1.64 & 2.21 \\
\hline Maximum & 56.19 & 35.05 & 59.22 \\
\hline Mean & 17.00 & 11.80 & 24.60 \\
\hline Std. deviation & 13.56 & 7.83 & 15.93 \\
\hline No. of districts & 25 & 28 & 23 \\
\hline
\end{tabular}

Table 6 brings out the fact that the minimum, maximum and mean ARE percent are $3.96 \%$, $56.19 \%$ and $17.0 \%$ respectively for Kuruvai season, followed by $1.64 \%, 35.05 \%$ and $11.80 \%$ respectively for Samba season and $2.21 \%, 59.22 \%$ and $24.60 \%$ respectively for Kodai season. The standard deviation varies from $7.83 \%$ in Samba season to $15.93 \%$ in Kodai season. Namakkal district showed the predicted rice production of -97 tonnes for 2009 (refer table A7) and hence it was omitted for prediction for want of more data. Similarly, Coimbatore district showed the predicted area of rice cultivation of -225 has (refer table A.3) and hence it was also omitted for further prediction for want of more input data. Nagapattinam district showed the high mean ARE percent of $581.49 \%$ due to the extreme ARE percent of $2832 \%$ for the year 2007 as per table A.4 in appendix. Hence, Nagapattinam district was also omitted for further prediction 
for want of more years of data to get consistent result. This caused the number of districts predicted in Kodai season is reduced to 23 districts.

\subsection{Test of significant difference between the FFBPNN and MLR methods}

The t-test as explained in section 3.5 is used to test the significance between two sets of paired data. The first data field is the FFBPNN method of predicted area of cultivation and the second data field is the MLR method of predicted area of cultivation. The two data items for a year form a pair. The same procedure is used to compute the $t$ value between the pair of FFBPNN and MLR methods of rice production.

\subsubsection{Paired $t$ test between the FFBPNN and MLR methods of predicted area}

The t-test was conducted as per section 3.5 between the FFBPNN and MLR methods of predicted area of rice cultivation. There are 25 observations for Kuruvai season. The table $t$ value for the degrees of freedom of 24 at $5 \%$ level of significance was taken up from the t table. If the calculated $t$ value is less than the table $t$ value then there is no significant difference between the two samples. This procedure is repeated for different years of rice cultivation for Kuruvai, Samba and Kodai seasons. The summary of the $t$ test is given in Table7.

Table 7 shows the fact that the calculated $t$ value is less than the table $t$ value at $5 \%$ level of significance for all the years in Kuruvai season, i-e there is 95\% confidence level between the FFBPNN and MLR methods of predicted area of rice cultivation. It is interpreted that there is statistically no significant difference between FFBPNN and MLR methods of predicted area of rice cultivation for the Kuruvai season.

With regard to the Samba season, the calculated $t$ value is less than the table $t$ value at $5 \%$ level of significance for all the years excepting 2007 and 2009. The predicted area of rice cultivation by FFBPNN method and MLR method are significantly different for 2007 and 2009. But, it is found that there is statistically no significant difference between FFBPNN and MLR methods of predicted area of rice cultivation for the years 2005, 2006 and 2008.

Table 7: Result of $\mathrm{t}$ test between the FFBPNN and MLR methods of predicted area of cultivation

\begin{tabular}{|c|c|c|c|c|c|c|c|c|c|}
\hline \multirow[t]{2}{*}{ Season } & \multirow{2}{*}{$\begin{array}{l}\text { No. of } \\
\text { districts }\end{array}$} & \multirow[t]{2}{*}{ DF } & \multirow{2}{*}{$\begin{array}{l}\text { Table t } \\
\text { at } 5 \% \\
\text { level }\end{array}$} & \multicolumn{5}{|c|}{$\begin{array}{l}\text { Calculated } t \text { value for area of cultivation } \\
\text { for different years }\end{array}$} & \multirow[t]{2}{*}{ Remarks } \\
\hline & & & & 2005 & 2006 & 2007 & 2008 & 2009 & \\
\hline Kuruvai & 25 & 24 & 2.064 & 1.673 & 1.949 & 1.884 & 1.968 & 1.615 & $\begin{array}{l}\text { No Significant } \\
\text { difference at } 5 \% \\
\text { level for all the years }\end{array}$ \\
\hline Samba & 28 & 27 & 2.052 & 1.665 & 1.101 & 4.022 & 0.104 & 2.742 & $\begin{array}{l}\text { Significant } \\
\text { difference for the } \\
\text { year } 2007 \text { and } 2009 .\end{array}$ \\
\hline Kodai & 26 & 25 & 2.056 & 3.065 & 2.845 & 3.725 & 1.624 & 0.654 & $\begin{array}{l}\text { Significant } \\
\text { difference for the } \\
\text { years } 2005,2006 \text {, } \\
\text { 2007. }\end{array}$ \\
\hline
\end{tabular}

Note: DF: Degrees of Freedom

With regard to the Kodai season, the calculated t value is less than the table $t$ value at $5 \%$ level of significance for the years 2008 and 2009. There is statistically no significant difference between the FFBPNN method of predicted area and MLR of predicted area for the years 2008 and 2009. 
For the year 2005, 2006 and 2007, it was found that the calculated t value is greater than the table $\mathrm{t}$ value, it means that there is statistically significant difference between the FFBPNN method and MLR of predicted area of cultivation for the year 2005,2006 and 2007.

The conclusion of the $t$ test shows that the idea of building MLR equations by taking the FFBPNN method of predicted area of cultivation as dependant variable (y) and the years of cultivation as independent variable (x) for the three seasons and the subsequent use of RDS to predict area of cultivation worked very well excepting for the 2007 in Samba season, 2005, 2006 and 2007 in Kodai seasons.

\subsubsection{Paired $t$ test between the FFBPNN and MLR methods of predicted rice production}

The paired t-test is used to test the significance between two sets of paired data items. The first data item is the FFBPNN method of predicted rice production and the second data item is MLR method of predicted rice production. The two data items form a pair. The calculated t value between the two sets of 25 observations for Kuruvai season was compared with the table t value at 24 degrees of freedom at $5 \%$ level of significance. If the calculated t value is less than the table $t$ value then there is no significant difference between the two samples. This procedure is repeated for 2005 to 2009 for Kuruvai, Samba and Kodai seasons. The summary of the $t$ test is given Table 8 .

Table 8 shows the fact that the calculated $\mathrm{t}$ value is less than the table $\mathrm{t}$ value at $5 \%$ level of significance for the years 2005,2006 and 2007 in Kuruvai season, 2005,2008 and 2009 in Samba season and 2006,2008 and 2009 in Kodai season. Hence, it is found that there is statistically no significant difference between the FFBPNN and MLR methods of predicted rice production for the years 2005,2006 and 2007 in Kuruvai season, 2005,2008 and 2009 in Samba season and 2006,2008 and 2009 in Kodai season respectively.

Table 8: Result of t test between the FFBPNN and MLR methods of predicted rice production

\begin{tabular}{|c|c|c|c|c|c|c|c|c|c|}
\hline \multirow[t]{2}{*}{ Season } & \multirow{2}{*}{$\begin{array}{l}\text { No. of } \\
\text { districts }\end{array}$} & \multirow[t]{2}{*}{ DF } & \multirow{2}{*}{$\begin{array}{l}\text { Table t } \\
\text { at } 5 \% \\
\text { level }\end{array}$} & \multicolumn{5}{|c|}{$\begin{array}{l}\text { Calculated } \mathrm{t} \text { for rice production for } \\
\text { different years }\end{array}$} & \multirow[t]{2}{*}{ Remarks } \\
\hline & & & & 2005 & 2006 & 2007 & 2008 & 2009 & \\
\hline Kuruvai & 25 & 24 & 2.064 & 1.771 & 0.472 & 0.006 & 2.719 & 6.300 & $\begin{array}{l}\text { Significant difference } \\
\text { for } 2008 \text { and } 2009 .\end{array}$ \\
\hline Samba & 28 & 27 & 2.052 & 1.007 & 2.472 & 2.160 & 1.685 & 1.759 & $\begin{array}{l}\text { Significant } \\
\text { difference for } 2006 \\
\text { and } 2007 \text {. }\end{array}$ \\
\hline Kodai & 26 & 26 & 2.056 & 2.916 & 1.817 & 3.421 & 1.699 & 0.095 & $\begin{array}{l}\text { Significant difference } \\
\text { for } 2005 \text { and } 2007 \text {. }\end{array}$ \\
\hline
\end{tabular}

Note: DF: Degrees of Freedom

Table 8 also shows the fact that the calculated $t$ value is greater than the table $t$ value at $5 \%$ level of significance for the years 2008 and 2009 in Kuruvai season, 2006 and 2007 in Samba season and 2005 and 2007 in Kodai season respectively. It is interpreted that there is statistically significant difference between the FFBPNN and MLR methods of predicted rice production. 


\section{SUMMARY AND CONCLUSIONS}

Prediction of annual rice production in all the 31 districts of Tamilnadu is an important decision for the Government of Tamilnadu. Rice production is a non linear and complex process involving soil, crop, weather, pest, disease, capital, labour and management parameters. FFBPNN software was designed and developed to predict area of cultivation and rice production. As per [2], the predicted results were found to be exactly equal to the observed values. It showed that the prediction was $100 \%$ accurate. Rice Data Simulator is software developed based on the MLR equations of the rice data. RDS used the inputs of FFBPNN predicted data and the years of rice cultivation and the output from the RDS is the MLR method of predicted data. The predicted data from the FFBPNN and MLR methods were tested using the $t$ test and also analyzed based on the ARE. The summary and conclusions drawn from the present research is given below:

1 The fitting of multiple regression equations between the years of rice cultivation and the area of cultivation/rice production is judged by the $r^{2}$ values. It was found that the $r^{2}$ values are widely varying between a minimum of 0 to a maximum of 0.99 . If the $r^{2}$ values are nearer to 1 , it means that the fitting is perfect. If the $\mathrm{r}^{2}$ values are nearer to 0 , it means the there is a poor fitting of the regression equation. The average $r^{2}$ value in area of cultivation is 0.40 in Kuruvai season, 0.42 in Samba season and 0.46 in Kodai season. The standard deviation of $r^{2}$ value in area of cultivation of rice varies from 0.25 in Kodai season to 0.35 in Kuruvai season. Similarly, it is also found that the average $r^{2}$ value in rice production is 0.31 in Kuruvai season, 0.23 in Samba season and 0.42 in Kodai season. The standard deviation of $r^{2}$ value in rice production varies from 0.23 in Samba season to 0.30 in Kuruvai season. The conclusion drawn from the results and discussion is that there is wide yearly variation of area of cultivation and rice production in some districts which is having the $r^{2}$ near to 0 . It is unavoidable in rice cultivation because of the reason that agriculture in Tamilnadu is a gamble with monsoon rains and also due to complexities of soil, weather, fertilizers, weeding, pests, diseases etc. The districts having $\mathrm{r}^{2}$ near to 1 have perfect prediction. The wide variations in some districts can be reduced if the input data is available for more number of years.

2 It was found that by using the MLR method of prediction, the average predicted area during Kuruvai season varies from 12052.52 ha to 13595.32 ha and the standard deviation varies from 10403.82 ha to 11070.78 ha. This gives the conclusion that the predicted area of rice cultivation gradually reduces from 2005 to 2009 during Kuruvai season. The average predicted area during Samba season varies from 48998.96 ha to 53324.54 ha and the standard deviation varies from 43865.85 ha to 46484.37 ha. The average predicted area for Kodai season varies from 4241.23 ha to 6449.88 ha and the standard deviation varies from 6484.13ha to 8939.42 ha.

3 With regard to the Kodai season, the minimum predicted area of rice cultivation varies from 225 ha for Coimbatore district in 2009 to 285 ha for Pudukottai district in 2007. The negative value of -225 ha cannot be acceptable prediction. Similarly, Namakkal district also has -62 ha. The reason for the negative prediction of area is mainly due to wide variations of observed area of cultivation for the five years, which causes the regression equation not true representative to provide the correct prediction. This type of error can be avoided only when more input is available to build the regression equation. It was also found that the negative prediction of area for Coimbatore and Namakkal districts during Kodai season only, there is no such problems encountered for other seasons and other districts.

4 It was found that for the Kuruvai season the range of minimum, maximum and average predicted rice production varies from 1747 tonnes to 4176 tonnes, 140620 tonnes to 144870 tonnes and 45132.88 tonnes to 46074.48 tonnes respectively. With regard to the Samba 
season, the range of minimum, maximum and average predicted rice production varies from 10173 tonnes to 15444 tonnes, 353250 tonnes to 398311 tonnes and 128619 tonnes to 139693.29 tonnes respectively. With regard to the Kodai season, the range of maximum and average predicted rice production varies 104884 tonnes in 2009 to 109903 tonnes in 2005 and 15446.07 tonnes to 20573.50 tonnes respectively where as the standard deviation varies from 22299.37 tonnes to 27967.16 tonnes.

5 With regard to the Kodai season, the range of minimum predicted rice production varies from -97 tonnes in 2009 for Namakkal district to 980 tonnes in 2007 for Pudokottai. The negative value of -97 tonnes cannot be acceptable prediction. The reason for the negative prediction of area is mainly due to wide variations of observed rice production, which causes the regression equation not true representative to provide the correct prediction. This type of error can be avoided only when more input data is available to build the regression equation.

6 It was found that the minimum, maximum and mean ARE percent for the area of rice cultivation was $2.04 \%, 63.48 \%$ and $15.58 \%$ respectively for Kuruvai season, $0.61 \%, 38.13 \%$ and $8.04 \%$ for Samba season and $2.61 \%, 58.71 \%$ and $26.34 \%$ for Samba season respectively. The reason for $63.48 \%$ error in Tiruvarur district in Kuruvai season,38.13\% error in Coimbatore district during Samba season and $58.71 \%$ error in Salem district during Kodai season are due to wide fluctuations in the observed data.

7 For the rice production, it was found that the minimum, maximum and mean ARE percent are $3.96 \%, 56.19 \%$ and $17.0 \%$ for Kuruvai season, $1.64 \%, 35.05 \%$ and $11.80 \%$ for Samba season and $2.21 \%, 59.22 \%$ and $24.60 \%$ for Kodai season respectively. The standard deviation varies from $7.83 \%$ in Samba season to $15.93 \%$ in Kodai season.

8 Namakkal and Coimbatore districts showed the predicted rice production of -97 tonnes for 2009 and -225 ha respectively. Nagapattinam district showed the high mean ARE percent of $581.49 \%$ due to the extreme data obtained for the year 2007. Hence, Namakkal, Coimbatore and Nagapattinam districts were omitted for further prediction during Kodai season due to want of more years of data to get consistent prediction.

9 The paired t test between the FFBPNN and MLR methods of predicted area of cultivation in Kuruvai shows that there is no significant difference between the two types of predictions. It was found for the Samba season, during 2007 and 2009 there is significant difference between FFBPNN and MLR methods of predicted area of cultivation. There is statistically no significant difference between the FFBPNN and MLR methods of predicted area for the three years 2005, 2006 and 2008 in Samba season. It was found for the Kodai season, during 2005, 2006 and 2007, there is significant difference between FFBPNN and MLR methods of predicted area of cultivation. There is statistically no significant difference between the FFBPNN and MLR methods of predicted area for the two years 2008 and 2009 in the Kodai season..

10 For the prediction of rice production, it was found that for the years 2005,2006 and 2007 in Kuruvai season, 2005,2008 and 2009 in Samba season and 2006,2008 and 2009 in Kodai season, there is insignificant difference between FFBPNN and multiple regression methods of prediction. It was also found that for the years 2008 and 2009 in Kuruvai season, 2006 and 2007 in Samba season, 2005 and 2007 in Kodai season showed that there is statistically significant difference between the FFBPNN method and the MLR methods of predicted rice production. The conclusion of the $t$ test shows that the idea of building the multiple linear regression equations by taking the FFBPNN method of predicted area of cultivation / rice production as dependant variable (y) and the years of cultivation as independent variable (x) for the three seasons and the subsequent RDS predicted area of cultivation /rice production worked very well excepting for some years due to wide variations in observed data which needs more input data for getting consistent results. 


\section{ACKNOWLEDGEMENTS}

The PhD scholar first and foremost thank the almighty God for his abundant blessings and protection during my studies and research work. I am highly indebted to Dr. K. Baskaran, my research Director and Associate Professor, Dept. of Computer Science \& Engineering and Information Technology, Government College of Technology, Coimbatore for his involvement, encouragement, suggestions and constructive criticism to make the research a grand success. I also thank the members of my research committee Dr. Ebenezer Jeyakumar, Director (Academic), Sri Ramakrishna College of Engineering, Vattamalaipalayam, Coimbatore and Dr. M. Hemalatha, Head of the Department of Software systems, Karpagam University Coimbatore for their suggestions and guidance to make my work more applied to the society.

\section{REFERENCES}

[1] Seasons and Crop Report for the years 2005-06 to 2009-10 (Fasli 1419), 2011 published by Government of Tamil Nadu. Department of Economics and Statistics, Chennai - 600 006, Report Number R.No. 6 / 2011.

[2] Arun Balaji, S and Baskaran, K [2013] Design and development of Artificial Neural Networking (ANN) system using sigmoid activation function to predict annual rice production in Tamilnadu published in International Journal of Computer Science, Engineering and Information Technology (IJCSEIT), Vol.3, No.1, February 2013.

[3] F. A. Makinde, C. T. Ako et al. [2012] Prediction of crude oil viscosity using Feed-Forward BackPropagation Neural Network (FFBPNN) published in the Journal of Petroleum \& Coal, ISSN $1337-$ 7027, Petroleum \& Coal 54 (2) 120-131 , 2012.

[4] A.Khashei-Siuki, M. Kouchakzadeh, and B. Ghahraman (2011) Predicting dry land wheat yield from meteorological data using expert system, Khorasan Province, Iran, published in the Journal of Agricultural Science and Technology: J. Agr. Sci. Tech. (2011) Vol. 13: 627-640.

[5] Sanjay R. Bhatikar, Roop L. Mahajan, Keith Wipke and Valerie Johnson [2000] Artificial Neural Network Based Energy Storage System Modeling for Hybrid Electric Vehicles, Paper No. 2000-011564, Copyright (C) 2000 Society of Automotive Engineers, Inc.

[6] Kavitha M.Mayilvaganan,.Naidu K.B, 2011, "ANN and Fuzzy Logic Models for the Prediction of groundwater level of a watershed", International Journal on Computer Science and Engineering, Vol. 3 No. 6, pp. 2523-2530.

[7] Karmakar, S., Kowar, M. K., Guhathakurta, P., 2009, Long-Range Monsoon Rainfall Pattern Recognition \& Prediction for the Subdivision 'EPMB' Chhattisgarh Using Deterministic \& Probabilistic Neural Network, IEEE Xplore 2.0, IEEE Computer Society, Washington, DC, USA, ISBN 978-0-7695-3520-3, pp. 376-370, Feb. 2009.

[8] Gyanesh Shrivastava, Sanjeev Karmakar, Manoj Kumar Kowar and Pulak Guhathakurta [2012] Application of Artificial Neural Networks in Weather Forecasting: A Comprehensive Literature Review published in the International Journal of Computer Applications (0975 - 8887) Volume 51No.18, August 2012

\section{Authors}

S. Arun Balaji, B.E and M.Tech Information Technology PhD Scholar, Computer Science \& Engineering, Karpagam University,Coimbatore, India. Teaching Experience: 5 years both India and Abroad.

Dr. K. Baskaran BE, ME, PhD, Associate Professor (CSE \& IT) Government College of Technology, Coimbatore- 641013, India

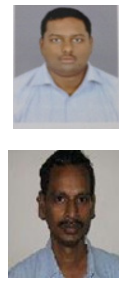


International Journal of Computer Science, Engineering and Information Technology (IJCSEIT), Vol. 4, No.5, October 2014

Appendix

Table A.1: FFBPNN method of predicted area of rice cultivation in different districts for three seasons

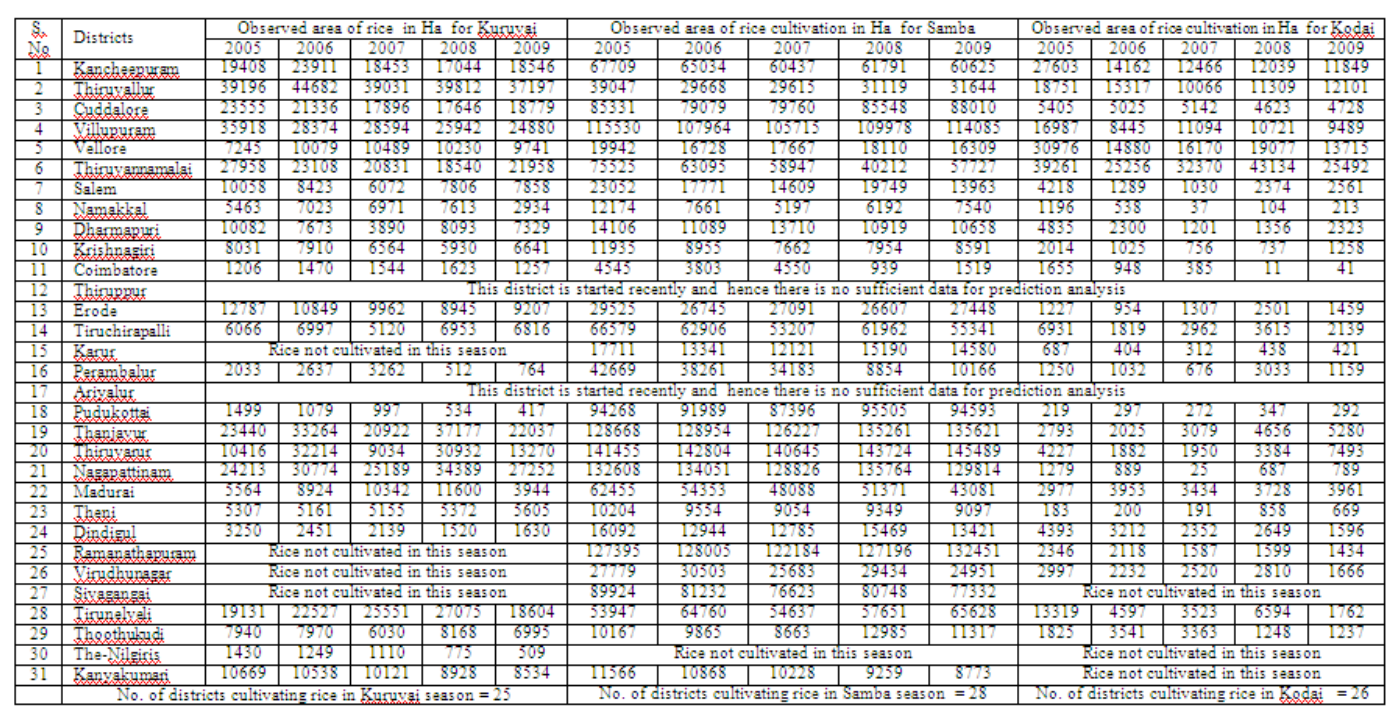

Table A.2: Multiple regression equations fitted for area of rice cultivation in different districts for three seasons

\begin{tabular}{|c|c|c|c|c|c|c|c|c|c|c|}
\hline \multirow[t]{2}{*}{ s.de } & \multirow[t]{2}{*}{ Districts } & \multicolumn{3}{|c|}{$\begin{array}{l}\text { Burfuva Ares in } \mathrm{y} \text { axis, years in } \mathrm{x} \text { axis } \\
\text { Equation: } \mathrm{yl}=\mathrm{al}+\mathrm{b} 1 \mathrm{x}\end{array}$} & \multicolumn{3}{|c|}{$\begin{array}{l}\text { Samba Area in } y \text { axis and years in } x \text { axis } \\
\text { Equation: } y 2=a 2+b 2 x\end{array}$} & \multicolumn{3}{|c|}{$\begin{array}{l}\text { Rodai Ara in } y \text { axis and years in } x \text { axis } \\
\text { Equation: } y 3=a 3+b 3 x\end{array}$} \\
\hline & & & & & & & & & & \\
\hline 1. & Bancharapuram & 1743686.00 & -859.10 & 0.27 & 3557506.75 & -1741.10 & 0.76 & 6765365.50 & -3363.10 & 0.62 \\
\hline 2. & Thirgyallyx & 1819791.12 & .886 .80 & 0.25 & 2712567.00 & -1335.50 & 0.29 & 3487224.50 & -1730.80 & 0.61 \\
\hline 3. & Cuddalere & 2677511.75 & -1324.20 & 0.68 & -2290133.25 & 1182.70 & 0.23 & 357413.81 & -175.60 & 0.77 \\
\hline 4. & Villuzurazam & 4947497.50 & -2450.80 & 0.81 & 286467.59 & -87.60 & 0.00 & 2564251.25 & -1272.00 & 0.37 \\
\hline 5. & Vellore & -1022643.25 & 514.30 & 0.38 & 1198670.00 & -588.40 & 0.43 & 6105191.00 & .3032 .50 & 0.47 \\
\hline 6. & Thiruxarnamalai & 3347676.75 & -1656.80 & 0.56 & 11795836.00 & -5847.90 & 0.53 & 1971864.62 & -966.00 & 0.04 \\
\hline & Salem & 1014955.31 & -501.70 & 0.31 & 3269168.75 & -1620.00 & 0.47 & 449654.69 & -222.90 & 0.08 \\
\hline 8. & Namakpkal & 902728.38 & -446.80 & 0.14 & 2162668.50 & -1073.70 & 0.40 & 482097.59 & -240.00 & 0.64 \\
\hline 9. & Dharmspuri & 1028173.62 & -508.60 & 0.13 & 1430242.50 & .706 .60 & 0.45 & 1200180.62 & .596 .80 & 0.42 \\
\hline 10. & Krishngagiri & 962347.19 & .476 .00 & 0.68 & 1552201.75 & .768 .90 & 0.51 & 362418.00 & -180.00 & 0.29 \\
\hline 11. & Coimbatore & -49758.50 & 25.50 & 0.05 & 1792512.38 & -891.60 & 0.67 & 836523.50 & -416.50 & 0.89 \\
\hline 12. & Thirgypzor & \multicolumn{9}{|c|}{ wly formed district. It has insufficient data to process and hence omitted } \\
\hline 13. & Erode & 1829494.88 & -906.40 & 0.85 & 888887.62 & -429.20 & 0.33 & -402118.12 & 201.10 & 0.29 \\
\hline 14. & Tifuchirapallij & .285828 .81 & 145.60 & 0.08 & 4760393.00 & .2342 .00 & 0.44 & 1566544.75 & .778 .80 & 0.36 \\
\hline 15. & Sarut & \multicolumn{3}{|c|}{ Rice not cultivated in this seas on } & 900277.69 & -441.30 & 0.11 & 100401.00 & .49 .80 & 0.32 \\
\hline 16. & 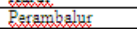 & 937705.69 & -466.30 & 0.39 & 18975516.00 & .9441 .30 & 0.86 & -363643.28 & 181.90 & 0.10 \\
\hline 17. & Arivalue & \multicolumn{9}{|c|}{ Newly formed district. It has no data to process and hence omitted } \\
\hline 18. & Budulegtai & 544601.50 & -270.90 & 0.96 & .743366 .00 & 416.60 & 0.04 & -39051.80 & 19.60 & 0.45 \\
\hline 19. & Thanjaxur & -194806.89 & 110.70 & 0.00 & -3925803.00 & 2021.30 & 0.57 & -1522756.88 & 760.50 & 0.79 \\
\hline 20. & Thirgyerys & .869125 .00 & 442.60 & 0.00 & -1661068.12 & 898.80 & 0.56 & -1608636.62 & 803.40 & 0.31 \\
\hline 21. & Nagrapattingm & -1917021.62 & 969.30 & 0.13 & 909925.12 & -387.50 & 0.04 & 237961.19 & -118.20 & 0.17 \\
\hline 22. & Madurai & 121269.60 & -56.40 & 0.00 & 8427081.00 & -4173.00 & 0.83 & -346209.50 & 174.30 & 0.44 \\
\hline 23. & Theni & -156644.89 & 80.70 & 0.48 & 494944.88 & -241.90 & 0.67 & -326720.81 & 163.00 & 0.65 \\
\hline 24. & Dindignl & 839317.69 & -417.10 & 0.89 & 579514.12 & -281.70 & 0.08 & 1238550.38 & -615.70 & 0.87 \\
\hline 25. & Ramangthargutam & \multirow{2}{*}{\multicolumn{3}{|c|}{$\begin{array}{l}\text { Rice not cultivated in this season } \\
\text { Rice not cultivated in this seasson }\end{array}$}} & -1739665.88 & 930.30 & 0.16 & 472056.91 & -234.30 & 0.89 \\
\hline 26. & Vifudhungagrar & & & & 1377377.50 & .672 .50 & 0.20 & 420703.78 & -208.40 & 0.40 \\
\hline 27. & 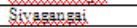 & \multicolumn{3}{|c|}{ Rice not cultivated in this seass on } & 5232739.50 & .2566 .80 & 0.59 & \multicolumn{3}{|c|}{ Rice not cultivated in this seas on } \\
\hline 28. & Tinunelyeli & .678668 .19 & 349.40 & 0.02 & -3202652.50 & 1625.30 & 0.21 & 4244141.00 & -2111.70 & 0.56 \\
\hline 29. & Therthuteudi & 347005.00 & -169.20 & 0.09 & -1077194.62 & 542.00 & 0.28 & 698471.06 & -346.90 & 0.24 \\
\hline 30. & The-Nilirisis & 465835.81 & .231 .60 & 0.98 & \multicolumn{3}{|c|}{ Rice not cultivated in this seas on } & \multicolumn{3}{|c|}{ Rice not cultivated in this season } \\
\hline 31. & Kanxalkumati & 1189874.00 & -588.00 & 0.92 & 1454175.25 & -719.50 & 0.99 & \multirow{2}{*}{\multicolumn{3}{|c|}{ No. of districts $\mathrm{cl}$}} \\
\hline & & \multicolumn{3}{|c|}{ No. of districts cultivating rice in Kuruxgi $=25$} & \multicolumn{3}{|c|}{ No. of districts cultivating rice in Samba $=28$} & & & \\
\hline
\end{tabular}


Table A.3: Predicted area of rice cultivation based on MLR equations in different districts for three seasons

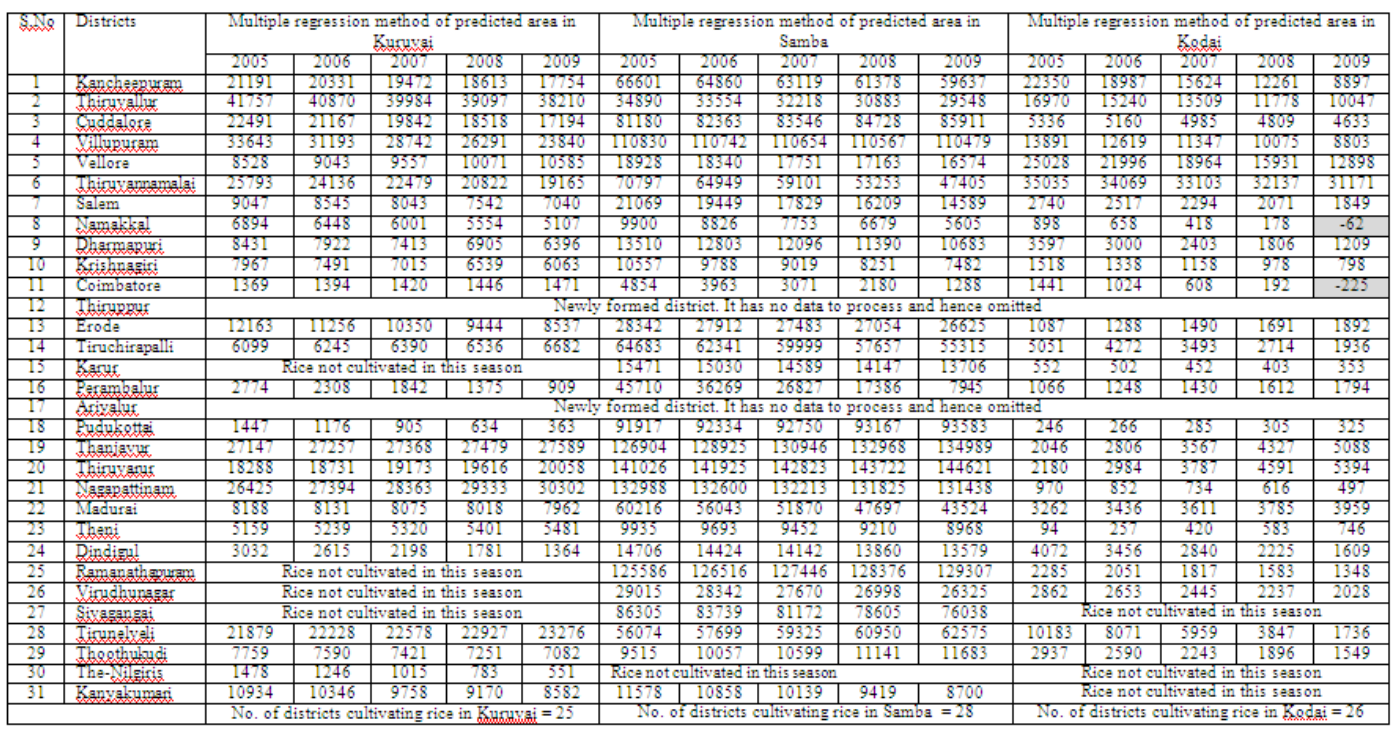

Table A.4: ARE percent between FFBPNN and MLR methods of predicted area of rice cultivation in different districts for three seasons

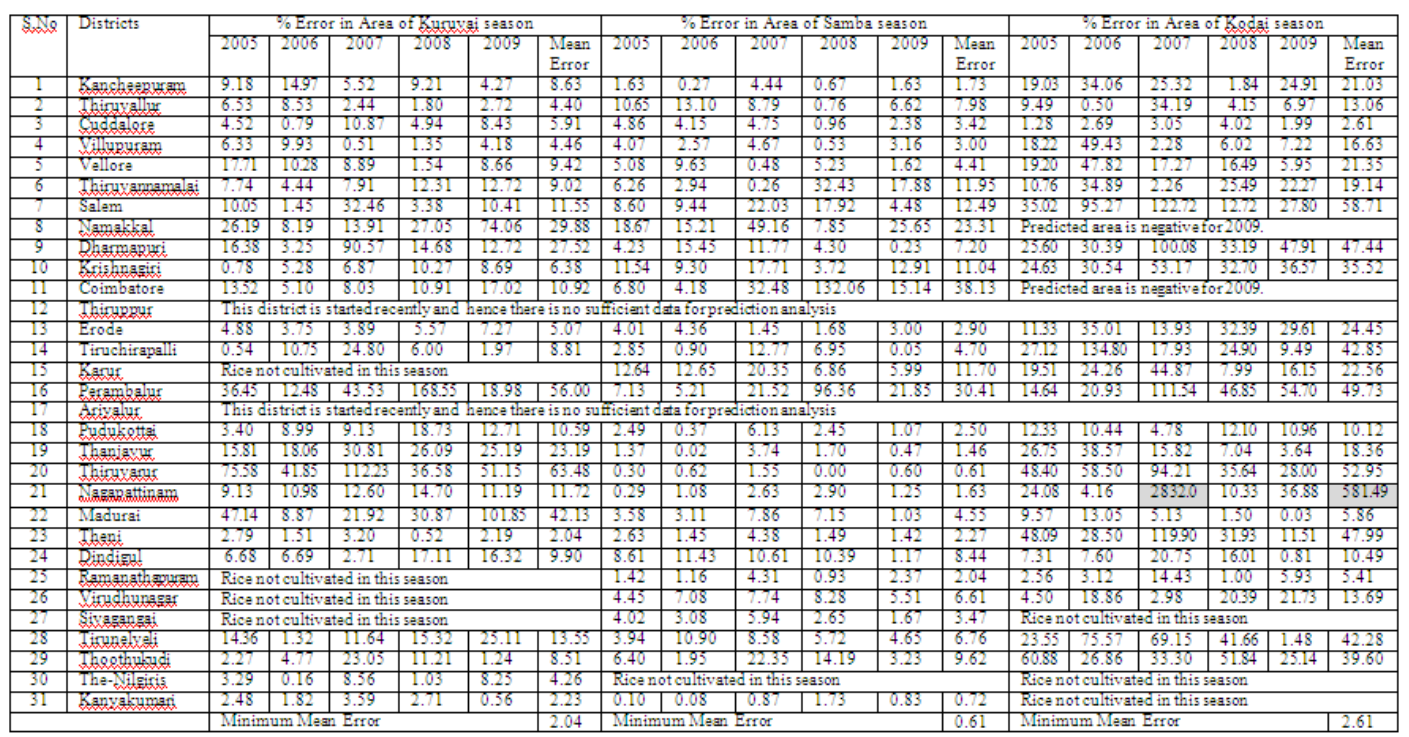


Table A.5: FFBPNN method of predicted rice production in different districts for three seasons

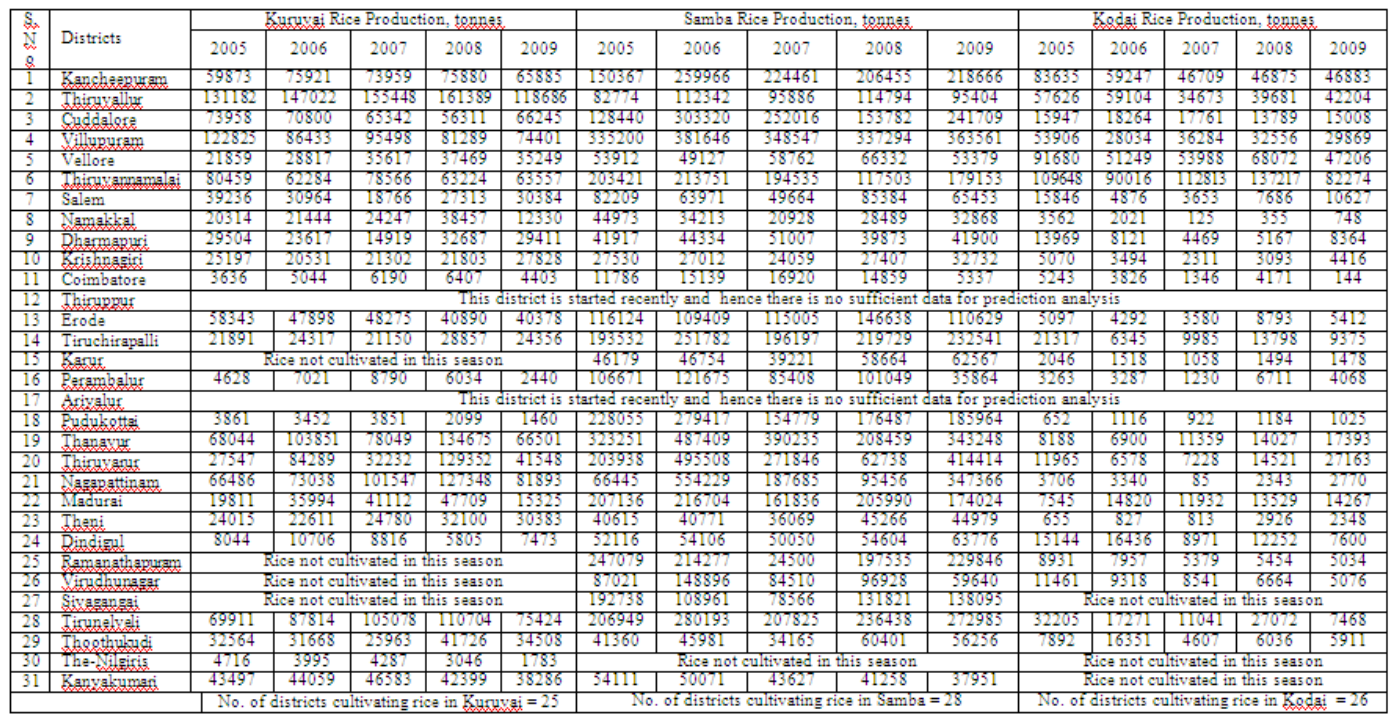

Table A.6: Multiple regression equations fitted for rice production in different districts for three seasons

\begin{tabular}{|c|c|c|c|c|c|c|c|c|c|c|}
\hline \multirow[t]{2}{*}{ s.Ne } & \multirow[t]{2}{*}{ Districts } & \multicolumn{3}{|c|}{$\begin{array}{l}\text { Kurduxa rice production in y axis, years in } x \text { axis } \\
\text { Equation: } y 4=a 4+b 4 x\end{array}$} & \multicolumn{3}{|c|}{$\begin{array}{c}\text { Samba rice production in y axis and yars in } x \text { axis } \\
\text { Equation: } y 5=a 5+b 5 x\end{array}$} & \multicolumn{3}{|c|}{$\begin{array}{l}\text { Kodgi rice production in } y \text { axis and years in } x \\
\qquad a x i s \\
\text { Equation: } y 6=a 6+b 6 x\end{array}$} \\
\hline & & a4 & b4 & $\mathrm{f}_{4}{ }^{2}$ & 35 & b5 & $\mathrm{rg}_{\mathrm{g}}{ }^{2}$ & 36 & b6 & $\mathrm{I}_{6}{ }^{2}$ \\
\hline 1 & Kanchaspuram & -2334684.50 & 1198.30 & 0.07 & -16463578.00 & 8308.70 & 0.11 & $172919 \$ 2.00$ & -8587.60 & 0.72 \\
\hline 2 & $\frac{1}{T}$ & 2275183.00 & .1062 .50 & 0.01 & -546155850 & 2771.20 & 0.11 & 10135245.00 & -5026.70 & 0.52 \\
\hline 3 & Cyddalore & 6070471.50 & -2991.50 & 0.50 & -15238047.00 & 7700.00 & 0.03 & 1291200.88 & -635.30 & 0.29 \\
\hline 4 & $\begin{array}{l}\text { Vortlupuram } \\
\text { Villupuram }\end{array}$ & 20561884.00 & -10199.20 & 0.73 & -2129409.50 & 1237.00 & 0.01 & 8777017.00 & .4355 .20 & 0.44 \\
\hline 5 & Vellora & -7079400.00 & 3543.20 & 0.75 & $-3182795,00$ & 1613.90 & 0.15 & 14537926.00 & -7212.50 & 0.40 \\
\hline 6 & Thiruyarnamalai & 6665422.50 & -3286.40 & 0.33 & 2923982200 & -14478.40 & 0.36 & 1621076.50 & .754 .70 & 0.00 \\
\hline 7 & Salem & 4315281.00 & -2135.50 & 0.21 & 2497605.50 & -1209.90 & 0.02 & 1539477.12 & .762 .80 & 0.06 \\
\hline 8 & Namalkpal & -186373.09 & 104.50 & 0.00 & 6040048.00 & -2993.40 & 0.29 & 1465268.00 & .729 .40 & 0.65 \\
\hline 9 & Dhasmaguri & -1756991.25 & 888.40 & 0.04 & 945952.69 & -449.50 & 0.03 & 2850732.75 & -1416.40 & 0.36 \\
\hline 10 & Krishngariri & -1288041.62 & 653.40 & 0.11 & -2139611.25 & 1079.90 & 0.30 & 346673.09 & -170.90 & 0.06 \\
\hline 11 & Coimbatore & .576291 .94 & 289.70 & 0.15 & 2657633.00 & -1317.80 & 0.21 & 1980443.12 & -985.30 & 0.54 \\
\hline 12 & Thirypzour & \multicolumn{9}{|c|}{ This district is started recently and hence thare is no sufficient data for prediction analysis } \\
\hline 13 & Erode & 8664813.00 & -4293.80 & 0.87 & -51.46606 .00 & 2623.90 & 0.07 & -1024356.88 & 513.10 & 0.16 \\
\hline 14 & Tiruchirapalli & -1876514.75 & 947.00 & 0.25 & -9006419.00 & 4596.50 & 0.09 & 3309865.75 & -1643.10 & 0.20 \\
\hline 15 & Karue & \multicolumn{3}{|c|}{ Rice not cultivated in this seas on } & .8917803 .00 & 4468.60 & 0.54 & 234330.80 & -116.00 & 0.27 \\
\hline 16 & Berambalur & 1082136.62 & -536.30 & 0.12 & 32651702.00 & -16224.00 & 0.60 & -1006612.00 & 503.40 & 0.16 \\
\hline & Arivalue & \multicolumn{9}{|c|}{ This district is started recently and hance there is no sufficient data for prediction analys is } \\
\hline 18 & Pudukettai & 1238253.12 & -615.50 & 0.78 & 37758316.00 & -18711.20 & 0.36 & -162390.00 & 81.40 & 0.38 \\
\hline 19 & $\frac{\text { Thangyyr }}{\text { Ther }}$ & -5476792.50 & 2773.80 & 0.02 & 48308988.00 & -23895.60 & 0.14 & -5113702.50 & 2553.70 & 0.89 \\
\hline 20 & Thiruxarut & -14601152.00 & 7306.50 & 0.07 & 2661561.50 & -1181.80 & 0.00 & .7681146 .00 & 3833.90 & 0.53 \\
\hline$\frac{21}{21}$ & Ng gappattingm & -16994326.00 & 8512.40 & 0.30 & -20435712.00 & & 0.01 & 578257.06 & -286.90 & 0.10 \\
\hline 22 & Madurai & -518529.88 & 274.30 & 0.00 & 15634594.00 & -7693.80 & 0.26 & -2426688.50 & 1215.30 & 0.43 \\
\hline 23 & Theni & .4433779 .50 & 2222.50 & 0.70 & -2612316.25 & 1322.30 & 0.31 & -1099325.75 & 548.50 & 0.69 \\
\hline 24 & Dindipgl & 1220998.88 & -604.30 & 0.28 & -4725342.50 & & 0.51 & 3879971.00 & -1927.20 & 0.64 \\
\hline 25 & Ramanathaydum & \multirow{2}{*}{\multicolumn{3}{|c|}{ Rice not cultivated in this seas on }} & 10460093.00 & -5120.80 & 0.01 & 2073158.75 & -1029.70 & 0.85 \\
\hline 26 & 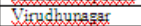 & \multirow{2}{*}{\multicolumn{3}{|c|}{$\begin{array}{l}\text { Rice not cultivated in this seas on } \\
\text { Rice not cultivated in this season }\end{array}$}} & 21516110.00 & -10673.00 & 0.26 & 3103808.75 & -1542.40 & 0.99 \\
\hline 27 & Six & & & & 17475734.00 & & 0.11 & \multicolumn{3}{|c|}{ Rice not cultivated in this seas on } \\
\hline 28 & 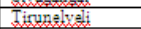 & -6717155.00 & 3391.60 & 0.09 & -17484344.00 & 8831.70 & 0.16 & 7981382.50 & -3967.30 & 0.36 \\
\hline 29 & Therthuly & .2765676 .25 & 1394.60 & 0.15 & -8825716.00 & 4421.20 & 0.42 & 2873553.25 & -1427.70 & 0.23 \\
\hline 30 & The-Nil siris & 1371335.88 & .681 .50 & 0.85 & \multicolumn{3}{|c|}{ litivated in the } & \multicolumn{3}{|c|}{ Rice not cultivated in this seas on } \\
\hline 31 & Banxalkumari & 2467822.00 & & & 8300796.50 & -4113.30 & 0.98 & & & \\
\hline & & \multicolumn{3}{|c|}{ 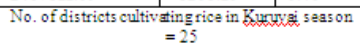 } & \multicolumn{3}{|c|}{$\begin{array}{l}\text { No. of districts cultivating rice in Samba seas on }= \\
\qquad 28\end{array}$} & \multicolumn{3}{|c|}{$\begin{array}{l}\text { No. of districts cultivating rice in Kodpas sason }= \\
26\end{array}$} \\
\hline
\end{tabular}


Table A.7: Predicted rice production based on MLR equations in different districts for three seasons

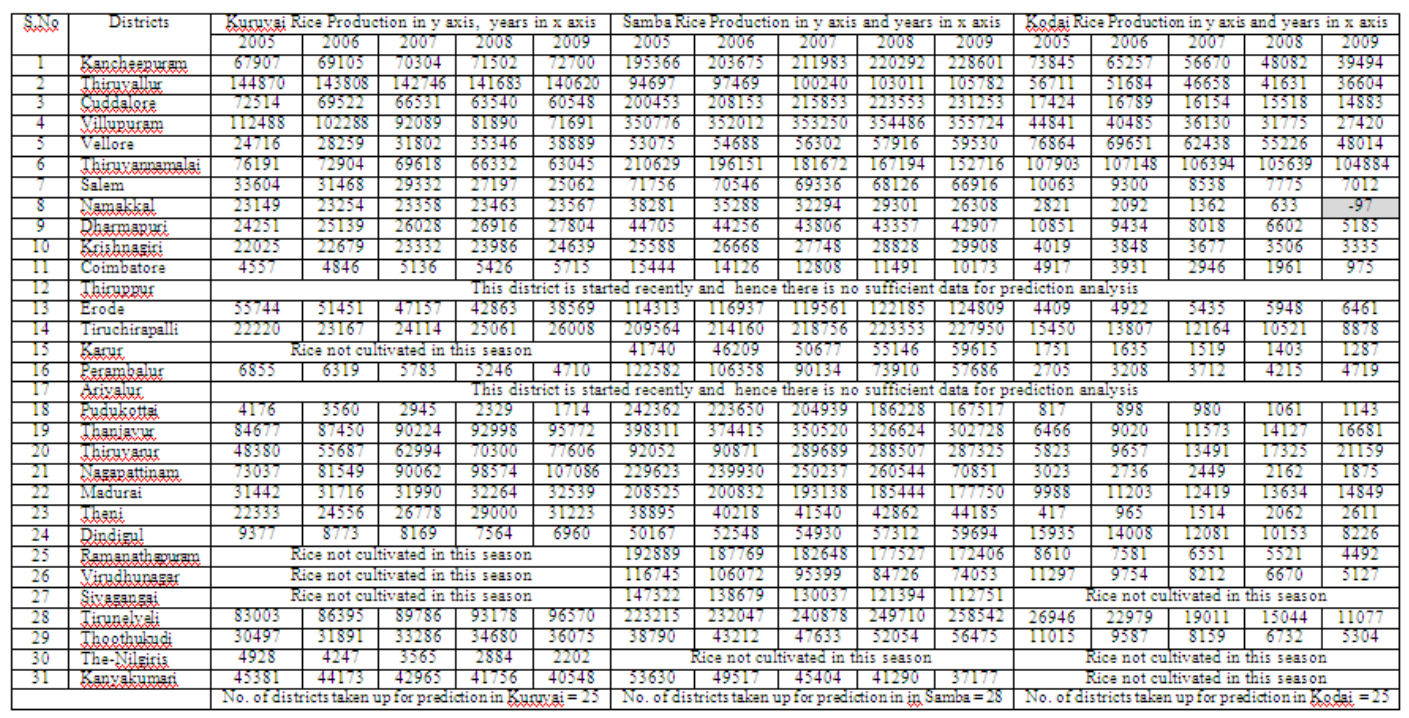

Table A.8: ARE percent between FFBPNN and MLR methods of predicted rice production in different districts for three seasons

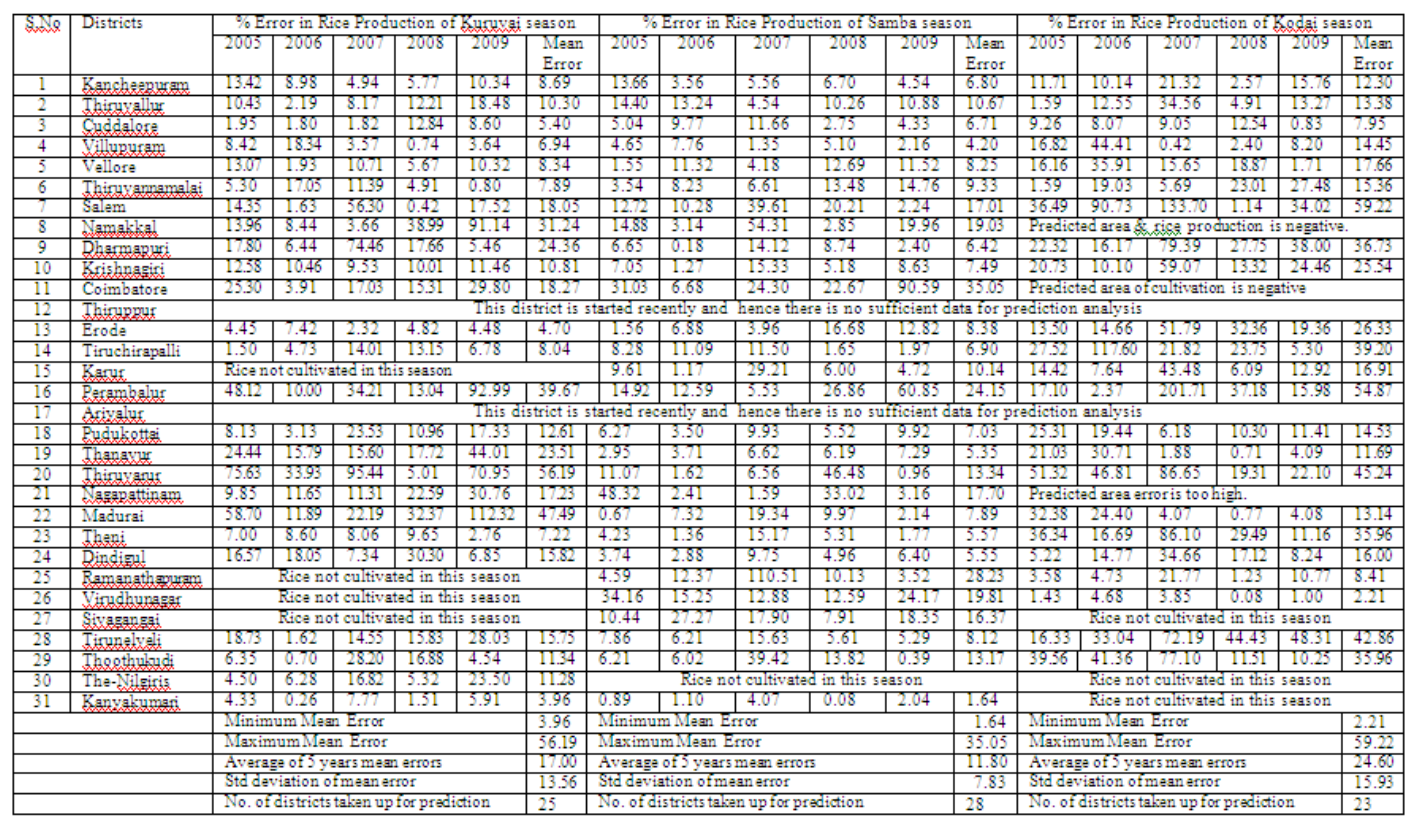

